\title{
A classic case of amyloid cardiomyopathy
}

\author{
Hayan Jouni, ${ }^{1}$ William G Morice, ${ }^{2}$ S Vincent Rajkumar, ${ }^{3}$ Joerg Herrmann ${ }^{4}$ \\ ${ }^{1}$ Department of Internal Medicine, Mayo Clinic, Rochester, Minnesota, USA \\ ${ }_{2}^{2}$ Department of Laboratory Medicine and Pathology, Mayo Clinic, Rochester, Minnesota, USA \\ ${ }^{3}$ Division of Hematology and Oncology, Department of Internal Medicine, Mayo Clinic, Rochester, Minnesota, USA \\ ${ }^{4}$ Division of Cardiovascular Diseases, Department of Internal Medicine, Mayo Clinic, Rochester, Minnesota, USA
}

Correspondence to Hayan Jouni, Mayo Clinic, 200 First Street SW, Rochester, MN 55905, Jouni.Hayan@mayo.edu

\section{DESCRIPTION}

A 55-year-old-woman with a history of hypertension, dyslipidemia and carpal tunnel syndrome had slowly progressive fatigue, weight loss, early satiety and diarrhoea over a 12-month period. She then developed several syncopal episodes attributed to orthostatic hypotension and one episode of cardiorespiratory arrest secondary to ventricular tachycardia. She was successfully resuscitated and was transferred to our hospital for further assessment.

Evaluation included an ECG which was significant for peripheral low-voltage ORS and pseudo-anteroseptalinfarction pattern (figure 1). Transthoracic echocardiogram showed an ejection fraction of $50 \%$ and a constellation of findings strongly suggestive of amyloidosis (figures 2 and 3 ; videos $1-5)$.

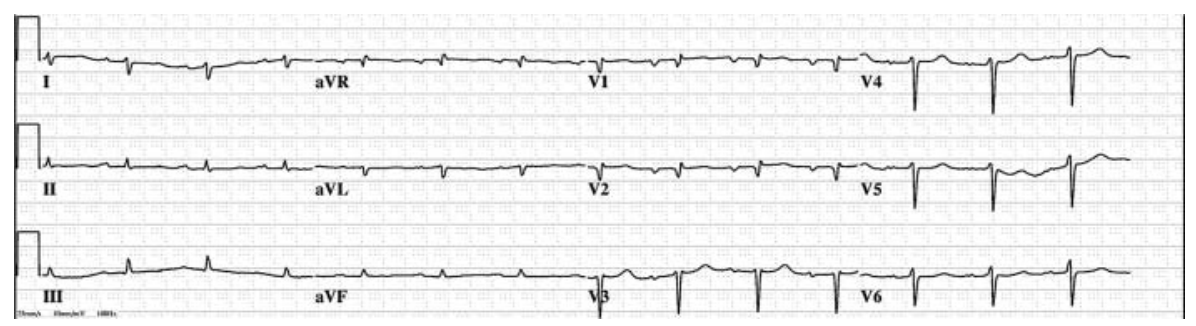

Figure 1 Twelve-lead ECG. This ECG was obtained at the time of admission and shows sinus rhythm with first-degree atrioventricular block. There was also left posterior fascicular block. The most remarkable finding was low-voltage ORS of the limb leads. There was poor $\mathrm{R}$ wave progression of the surface leads with non-specific ST segment and T wave changes.
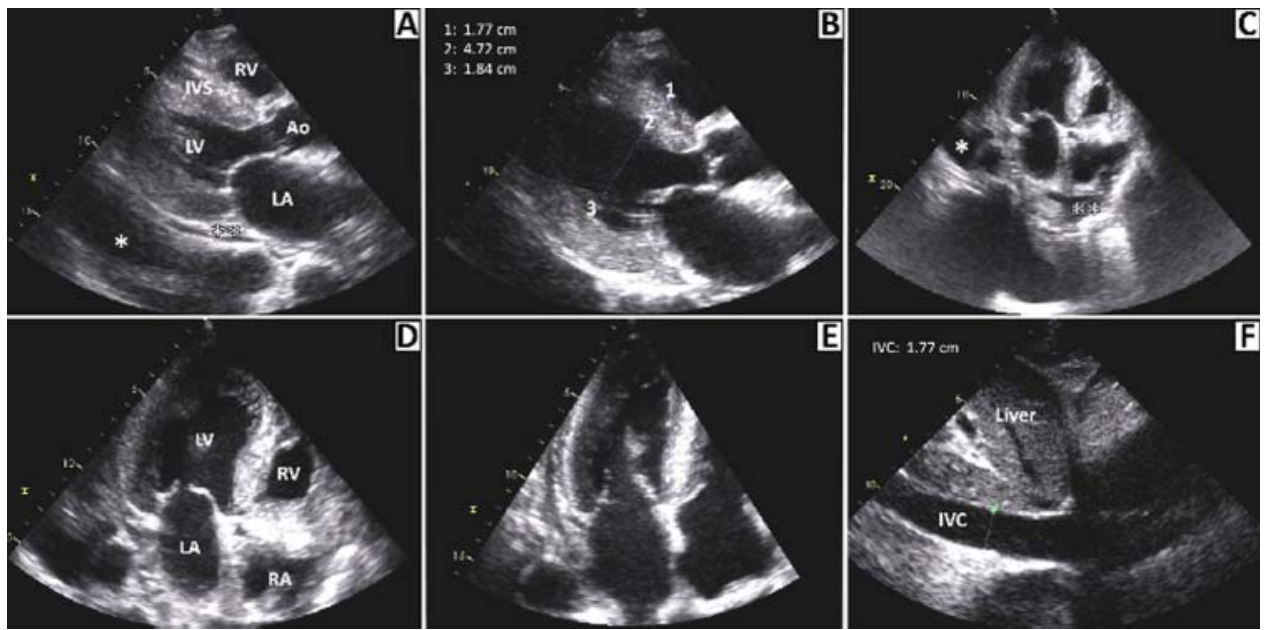

Figure 2 Transthoracic echocardiogram two-dimensional still images. (A and B) Parasternal long-axis views demonstrating thickening of the left ventricle (LV) myocardium as well as the interventricular septum (IVS). Also seen in these images are a large pleural effusion $\left({ }^{*}\right)$ and a small pericardial effusion $\left({ }^{* *}\right)$. (C-E) Four-chamber apical views showing clear right ventricle wall thickening in addition to thickened echo-bright myocardium of the LV and IVS. Again the pleural effusion $\left(^{*}\right)$ and small pericardial effusion $\left({ }^{* *}\right)$ are seen in these views. (F) Epigastric view to assess the liver and inferior vena cava (IVC). The IVC is moderately dilated with reduced inspiratory collapse $(<50 \%)$ as demonstrated in the videos $1-5$. 


\section{BMJ Case Reports}

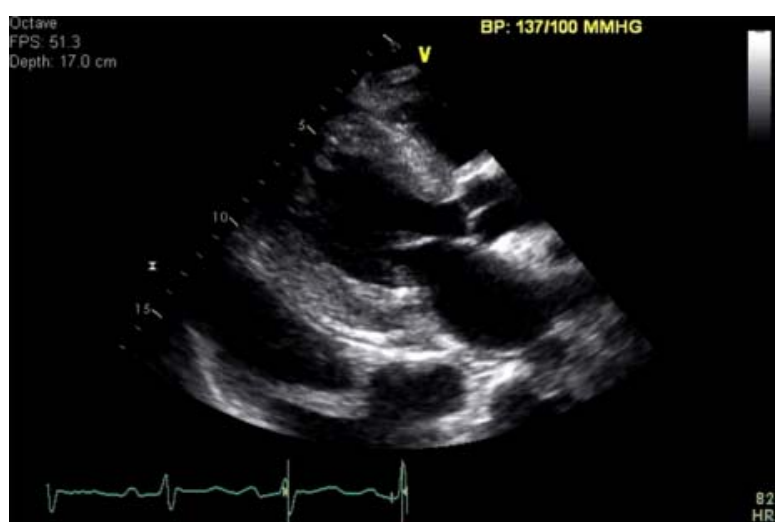

Video 1 Parasternal long-axis clip demonstrating the thickened myocardium of the left ventricle and interventricular septum. The pleural effusion is visualised in this clip as well as a small pericardial effusion.

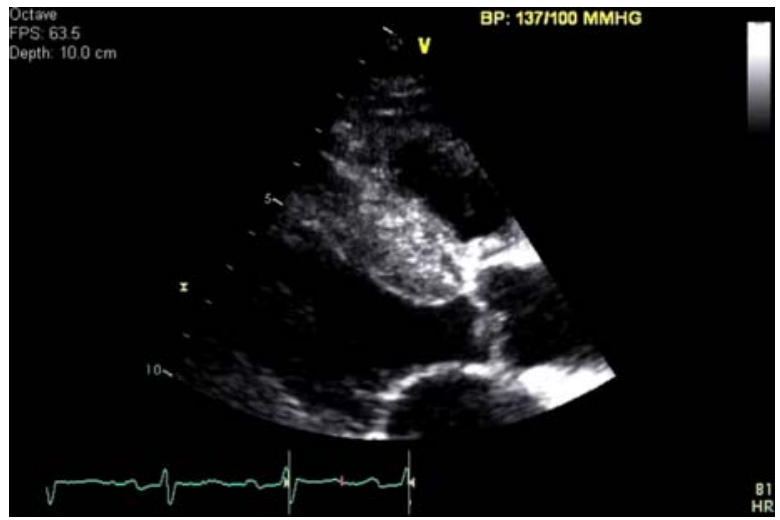

Video 2 Parasternal long-axis clip magnified to illustrate the interventricular septum. This clip clearly demonstrates the echo-bright myocardium of the septum in a 'speckled' pattern.

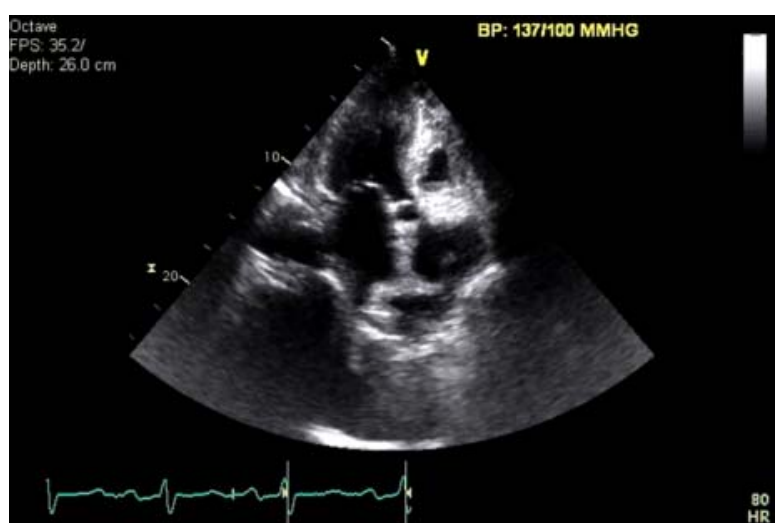

Video 3 Apical four-chamber clip demonstrating the thickened echo-bright myocardium with involvement of the right ventricle as well. Again the pleural effusion and pericardial effusion can be visualised here.

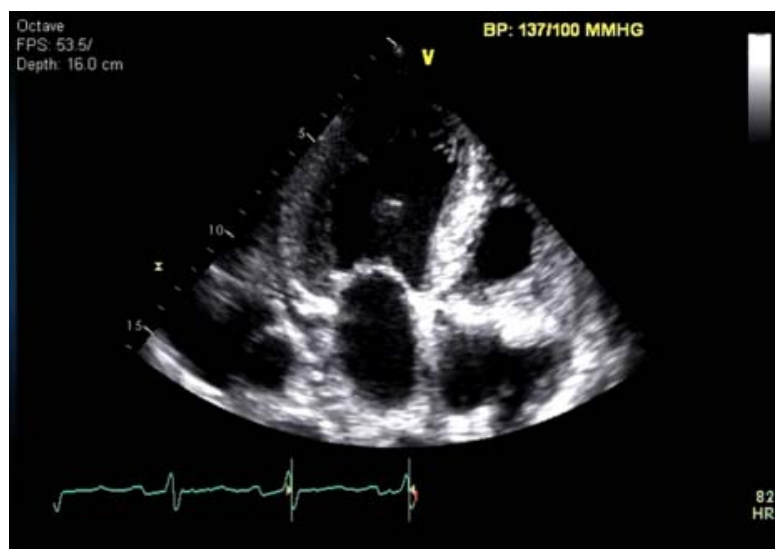

Video 4 Apical four-chamber view zoomed to better delineate the myocardial changes.

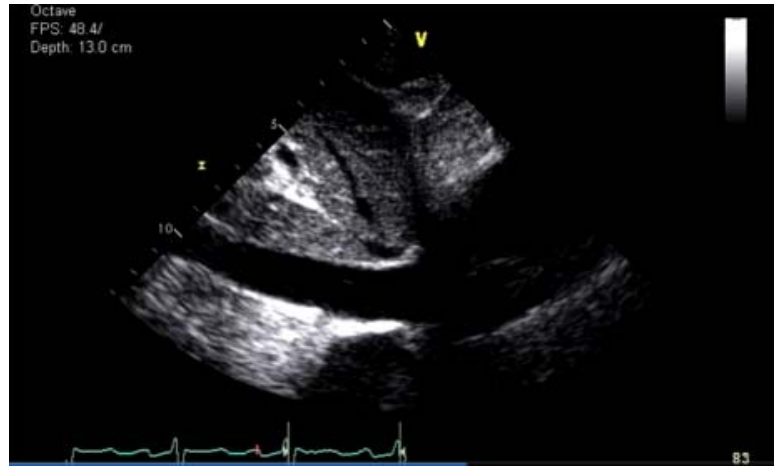

Video 5 This epigastric view shows a moderately dilated inferior vena cava with reduced inspiratory collapse $(<50 \%)$ indicative of a restrictive process involving the right ventricle.

Abdominal fat aspirate demonstrated amyloid deposition with Congo red staining; submucosal amyloid deposition was also identified in a gastric biopsy obtained 1 year earlier at the time of an upper endoscopy (figures 4 and 5). The amyloid was confirmed to be of lambda-light chain type by mass spectroscopy. A bone marrow biopsy revealed slight marrow plasmacytosis (5-10\%) without definite immunoglobulin light chain restriction. Serum and urine free light chains were elevated. Serum N-terminal prohormone brain natriuretic peptide was $20977 \mathrm{pg} / \mathrm{ml}$ and serum cardiac troponin- $\mathrm{T}$ was $0.12 \mathrm{ng} / \mathrm{ml}$. Elevation of these cardiac biomarkers indicates poor outcomes in patients with primary systemic amyloidosis. ${ }^{1}$

Unfortunately, she was ineligible for combined stem cell and cardiac transplant given her multiorgan involvement with amyloidosis. She was started on prednisone and melphalan, and an implantable cardioverter defibrillator was placed for secondary prevention. $\beta$-Blocker and ACE inhibitor therapy were reinitiated but require careful titration in these patients. 


\section{BMJ Case Reports}

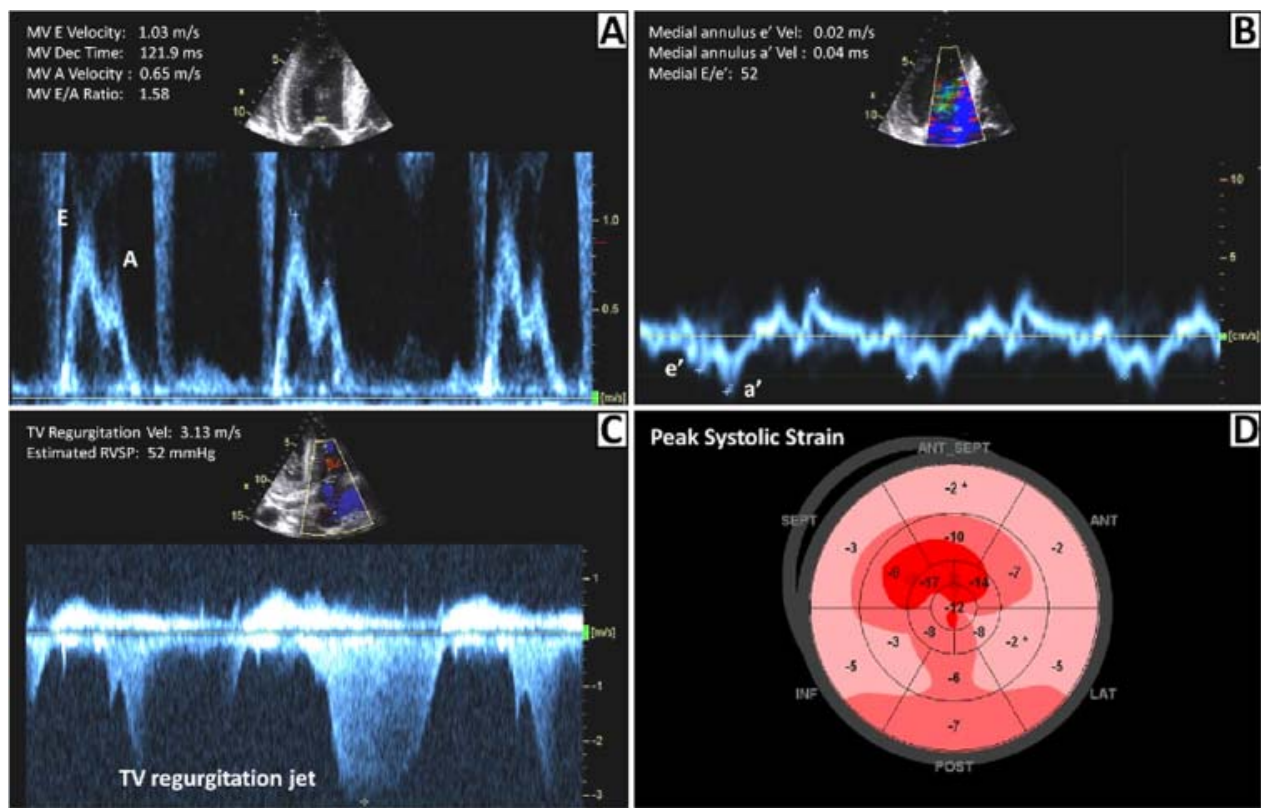

Figure 3 Transthoracic echocardiogram Doppler and strain analysis. (A) Mitral valve (MV) pulse wave Doppler profile showing an E/A ratio of 1.58 along with a reduced deceleration time (MV Dec time) of $121.9 \mathrm{~ms}$ (reference range: 157-245 ms). (B) Tissue Doppler imaging of the medial mitral annulus showing diminished $\mathrm{e}^{\prime}$ velocity (E/e' ratio 52$)$. Findings presented in $(\mathrm{A})$ and $(\mathrm{B})$ are indicative of a restrictive left ventricular filling pattern and grade III-IV diastolic dysfunction consistent with severely elevated left ventricular filling pressures. $^{3}$ (C) Tricuspid valve (TV) pulse wave Doppler compatible with moderate pulmonary hypertension. (D) Myocardial strain imaging demonstrated markedly reduced global averaged left ventricle longitudinal peak systolic strain at $-7 \%$ suggestive for myocardial impairment (normal $<-18 \%$ ).

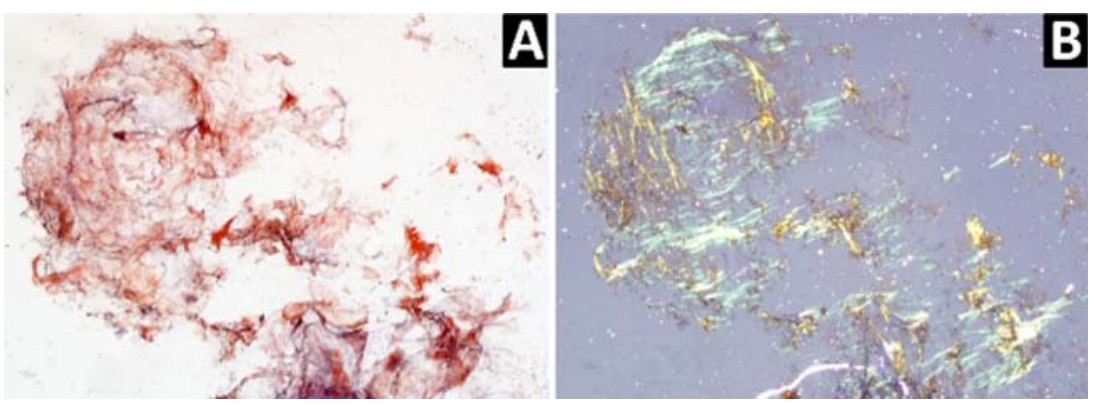

Figure 4 Abdominal fat pad aspirate pathology slides. (A) Positive staining of the abdominal fat pad aspirate with Congo red stain. (B) Classic apple-green appearance of Congo red-stained amyloid when viewed under polarised light. 


\section{BMJ Case Reports}

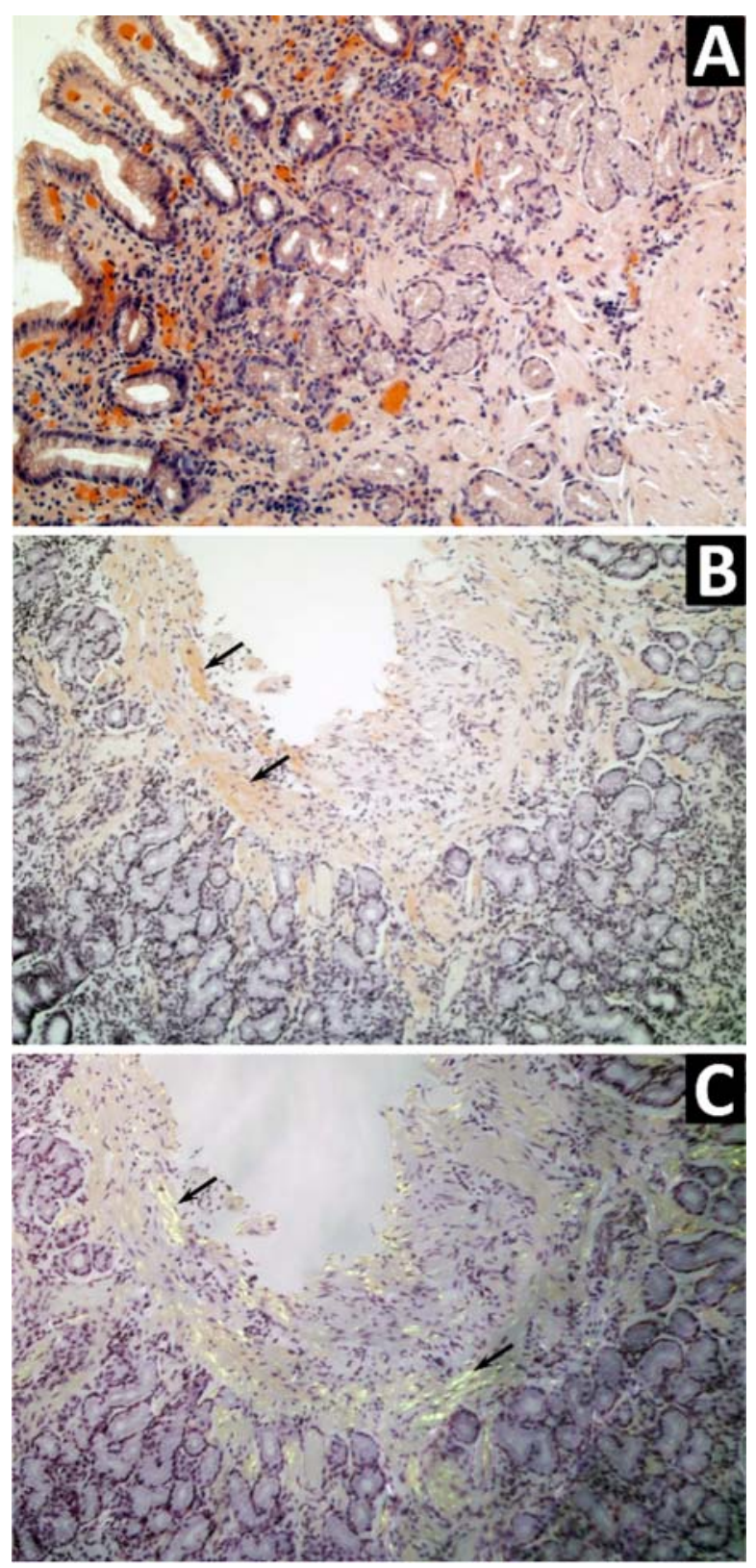

Learning points

- Low-voltage QRS and pseudo-anteroseptal-infarction pattern on ECG along with thickened, echo-bright myocardium on echocardiography should always raise suspicion for an infiltrative process such as amyloidosis.

- Elevation of serum $\mathrm{N}$-terminal prohormone brain natriuretic peptide and Troponin-T is associated with poor outcomes in patients with primary systemic amyloidosis. ${ }^{1}$ Reduced longitudinal peak systolic myocardial strain on echocardiography is also associated with adverse outcomes in patients with primary AL amyloidosis. ${ }^{2}$

\section{Competing interests None.}

Patient consent Obtained

\section{REFERENCES}

1. Dispenzieri A, Gertz MA, Kyle RA, et al. Prognostication of survival using cardiac troponins and $\mathrm{N}$-terminal pro-brain natriuretic peptide in patients with primary systemic amyloidosis undergoing peripheral blood stem cell transplantation. Blood 2004;104:1881-7.

2. Koyama J, Falk RH. Prognostic significance of strain Doppler imaging in light-chain amyloidosis. JACC Cardiovasc Imag 2010;3:333-42.

3. Lester SJ, Tajik AJ, Nishimura RA, et al. Unlocking the mysteries of diastolic function: deciphering the Rosetta Stone 10 years later. J Am Coll Cardiol 2008;51:679-89.

Figure 5 Gastric biopsy pathology slides (A) H\&E.

(B) Amorphous submucosal deposits of amyloid detected with Congo red stain. (C) The previously described amorphous deposits again show the characteristic apple-green appearance when examined under polarised light (black arrows). 


\section{BMJ Case Reports}

This pdf has been created automatically from the final edited text and images.

Copyright 2012 BMJ Publishing Group. All rights reserved. For permission to reuse any of this content visit http://group.bmj.com/group/rights-licensing/permissions.

BMJ Case Report Fellows may re-use this article for personal use and teaching without any further permission.

Please cite this article as follows (you will need to access the article online to obtain the date of publication).

Jouni H, Morice WG, Rajkumar SV, Herrmann J. A classic case of amyloid cardiomyopathy. BMJ Case Reports 2012;10.1136/bcr-2012-006937, Published XXX

Become a Fellow of BMJ Case Reports today and you can:

- Submit as many cases as you like

- Enjoy fast sympathetic peer review and rapid publication of accepted articles

Access all the published articles

- Re-use any of the published material for personal use and teaching without further permission

For information on Institutional Fellowships contact consortiasales@bmjgroup.com

Visit casereports.bmj.com for more articles like this and to become a Fellow 